\title{
Transtorno de Pânico: Uma Manifestação Clínica do Desamparo
}

\author{
Panic Disorder: A Clinical \\ Manifestation of Helplessness \\ Trastorno de Pánico: Una Manifestación \\ Clínica del Desamparo
}
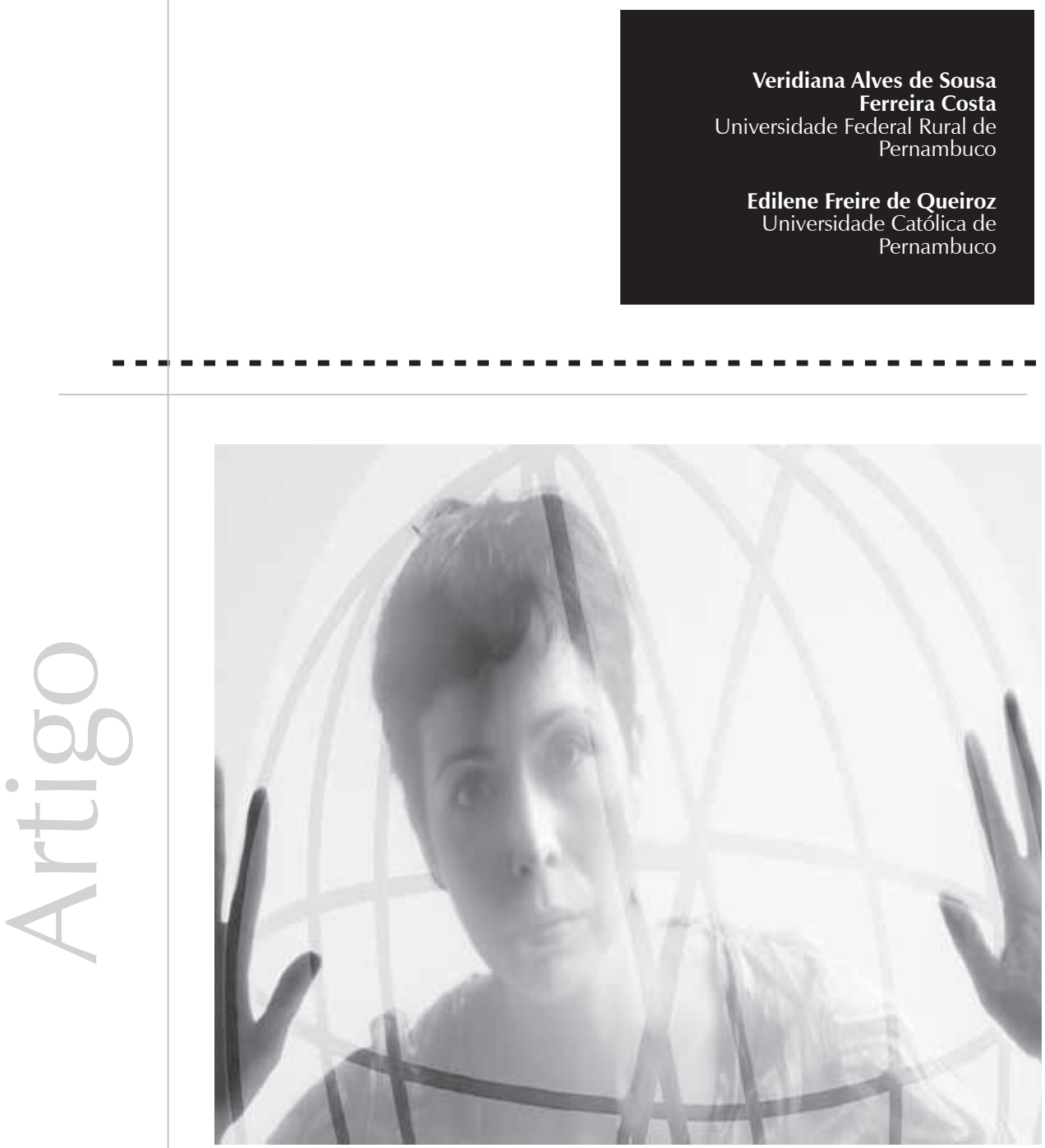
Resumo: O contexto atual apresenta mudanças nos modos de organização subjetiva. As redefinições dos papéis do homem e da mulher, as novas formas de filiação e as novas configurações familiares tem implicado o redimensionamento do lugar do pai e se refletido no exercício de sua função, qual seja, inscrever a lei. Tal inscrição é fundamental à estruturação do ser humano e à convivência social. Na atualidade, o sujeito se vê convocado ao excesso, sem referências, e novas formas de desorganização psíquica emergem. O transtorno de pânico se destaca como uma figura paradigmática do desamparo na contemporaneidade. Como categoria psicopatológica, tal transtorno é recente; como quadro clínico psicanalítico, ele se associa às fobias. Este estudo teórico visa a descrever, do ponto de vista da psiquiatria, tal transtorno, e discutir, a partir da psicanálise, o estado de desamparo provocado pela fragilidade da lei simbólica, como característica dessa sintomatologia.

Palavras-chave: Desamparo. Fobias. Distúrbio do pânico. Psicanálise.

Abstract: These days it is possible to observe changes in the subjective organization modes. The redefinition of the roles of men and women and the new modalities of filiation have changed the father's role, and this has been reflected in the actual performance of being a father, namely, in passing the law. This is fundamental for the structuring of a human being and for his/her social co-existence. Nowadays, the self seems to have no sense of limits, no landmarks and new ways of psychic disorganization arise with that. Panic disorder can be seen as a main paradigm of helplessness in our time. As a psychopathologic category, this disorder is new; as a psychoanalytical clinical record, it is associated to phobias. The present study aims to describe, from a psychiatric point of view, such disorder and discuss, based on psychoanalysis, the state of helplessness, caused by the fragility of the symbolic law as a characteristic of this symptom.

Keywords: Helplessness. Phobias. Panic disorder. Psychoanalysis.

Resumen: El contexto actual presenta cambios en las formas de organización subjetiva. Las redefiniciones de las atribuciones del hombre y de la mujer, las nuevas formas de filiación y las nuevas configuraciones familiares han conllevado al redimensionamiento del lugar del padre y se han reflejado en el ejercicio de su función, la cual es la de inscribir la ley. Dicha transcripción es fundamental a la estructuración del ser humando y a la convivencia social. En la actualidad, el sujeto se ve convocado a lo extremo, sin referencias, y nuevas formas de organización psíquica emergen. El trastorno de pánico se destaca como una figura con características de paradigma del desamparo en la contemporaneidad. Como categoría psicopatológica, dicho trastorno es reciente; como cuadro clínico psicoanalítico, él se asocia a las fobias. Este estudio teórico tiene como objetivo describir, desde el punto de vista de la psiquiatría, dicho trastorno, y discutir, a partir del psicoanálisis, el estado de desamparo provocado por la fragilidad de la ley simbólica, como característica de esa sintomatología.

Palabras clave: Desamparo. Fobias. Trastorno de pánico. Psicoanálisis.

Nos últimos tempos, o mundo vem passando por um processo acelerado de transformações. São mudanças de valores, de condições de procriação, de filiação, dos papéis de homem e de mulher, de configurações familiares, da forma de educar os filhos, enfim, reposicionamentos sociais que revelam estar a espécie humana atravessando uma crise de referências que produz efeitos diversos nos modos de organização subjetiva.

Tais questões nos fazem interrogar as repercussões da destituição do pai como figura central na organização da lei e como os sujeitos estão se organizando na referência à ordem cultural e à simbólica. Cabe, então, refletir sobre a fragilidade da lei do pai na contemporaneidade e sobre sua relação com o sentimento de desamparo, frequentemente observado no contexto atual. Uma das manifestações desse desamparo está conotada no transtorno de pânico, como configuração clínica atual. No nosso entender, como figura clínica, ele representa uma variação moderna do quadro fóbico que mostra, mais claramente, a relação atual da fragilidade da lei simbólica com o desamparo.

O estabelecimento da lei se institui como um modo de amparo simbólico aos sujeitos, pois, ao mesmo tempo em que priva e limita, protege e ampara. Essa relação entre lei e amparo é 
essencial à vida em comunidade, tal como Freud (1913/1975c) apontou em Totem e Tabu. Sem dúvida, as mudanças no referencial de lei têm trazido repercussões nos modos de organização subjetiva, levando a uma crise de referências simbólicas e criando novas formas sintomáticas de mal-estar.

Para Lacan(1999), o referencial simbólico no qual a lei se representa é a função paterna. Por tal razão, sua noção de pai tem uma conotação bastante particular, diferentemente do que é em geral concebido por outros campos do conhecimento que se relaciona mais à filiação biológica ou ao seu papel social. Na perspectiva lacaniana, pai é alguém investido de legítimo poder de intervenção estruturante; do ponto de vista do inconsciente, é uma entidade essencialmente simbólica que ordena uma função. Para entender a problemática da questão paterna, Lacan (1995) destaca uma sucessão lógica de diferentes investimentos da figura paterna na dinâmica edipiana e todas as consequências psíquicas. No centro da vivência edipiana, encontra-se a referência à função do pai.

Lembremos que, em princípio, a criança tem um tipo de relação com a mãe diante da qual o pai, como pai real, é um estranho. Nenhuma instância exterior é capaz de poder mediatizar os móbeis do desejo. Essa indistinção resulta do fato de que o filho constitui o único objeto que pode satisfazer o desejo da mãe. De fora desse circuito, o pai real não pode assumir sua função simbólica. Enquanto o filho fica nesse lugar de objeto suscetível de satisfazer o desejo da mãe, ele está identificado com o seu falo. Mas, no momento em que percebe o pai como um intruso, ele começa a se questionar acerca da sua identificação imaginária com o objeto do desejo da mãe, surgindo uma incerteza quanto ao seu lugar no desejo dela, e isso o leva a confrontar-se com o registro da castração simbólica pela instância paterna. Devido a esse confronto com a castração, cada vez mais o pai real surge diante da criança como aquele que tem direitos sobre a mãe. Entra em jogo a rivalidade fálica, e a figura paterna será investida como um pai privador, interditor e frustrador (Dor, 1991).

Entretanto, de rival junto ao desejo da mãe, o pai passa a ser visto como aquele que ela deseja, como um falo rival. Nesse jogo, esboça-se a atribuição fálica paterna, pois ele agora é visto como aquele que supostamente tem o falo. A partir daí, a criança é conduzida ao encontro com a lei do pai. Pela via do pai imaginário, o pai real assume a representação de pai simbólico, investido como aquele que tem o falo.

No seminário As formações do inconsciente, proferido entre 1957 e 1958, Lacan (1999) define o papel normatizante do pai no complexo de Édipo e expõe a operação de substituição, introduzindo a fórmula da metáfora paterna. A operação consiste em designar uma coisa pelo nome de outra, com base em uma substituição significante em que o de origem - a mãe - é provisoriamente recalcado em benefício do surgimento de outro significante - o pai. Assim, a referência ao pai, associada ao desejo da mãe, emerge como o significante Nome-do-Pai. Por conseguinte, inscreve-se a lei, e o pai surge como seu representante simbólico. O Nomedo-Pai é, pois, o significante da função paterna, uma chave que abre ao sujeito o acesso ao simbólico, que lhe permitirá nomear seu desejo.

Não podemos esquecer que a instância do pai simbólico é, antes de mais nada, a referência à lei da proibição do incesto, que prevalece sobre todas as regras concretas que legalizam as relações e as trocas entre os sujeitos de uma mesma comunidade. Como agente da castração, ele interdita, institui a lei e põe limite ao gozo, propiciando a renúncia pulsional e abrindo espaço para a emergência do sujeito desejante. É a lei simbólica que permite ao sujeito renunciar à plena realização das pulsões, ganhando, em troca, segurança. Esse pacto o capacita a estabelecer relações de troca e a lidar com o desamparo, pois, ao mesmo tempo em que limita o gozo, oferece benefícios compensatórios ao sujeito. Estar 
referido à lei, dentre outras coisas, implica obter ganhos secundários importantes. Se a lei humaniza o homem e lhe dá o amparo de que tanto necessita, o que ocorre quando ela falha? Várias consequências são possíveis, mas uma delas - a que destacamos aqui - é que o sujeito fica desamparado, e, então, o pânico encontra espaço suficiente para se instalar, pois a paisagem atual não parece oferecer benefícios ao sujeito que compense a renúncia pulsional e, assim, ele parece viver a encruzilhada de ficar à mercê das exigências pulsionais vivendo o excesso, ou renunciar a tais exigências enfrentando o desamparo sem recompensas, sem segurança.

Sabemos da importância que Freud deu à civilização. Para ele (1930/2006), a cultura deveria conter determinados impulsos pulsionais e oferecer vantagens como recompensa, para garantir o bem-estar comum. Naquela época, ele destacou que o contexto social era muito repressor, gerador de neuroses. Atualmente, o contexto se mostra muito permissivo, e essa permissividade prejudica o processo de instalação e de manutenção da lei. Sustentamos que uma lei falha desampara os homens, e o ambiente de desamparo favorece o aparecimento dos sentimentos de pânico.

A instauração de um estado de desamparo é o perigo fundamental do qual o aparelho psíquico foge. Porém, conforme Pereira (1999, p. 253), "se, por um lado, o desamparo constitui o horizonte necessário, não acidental do funcionamento psíquico, nem por isso o sujeito se encontra sempre em uma situação efetiva de desamparo".

A condição humana de desamparo independe de situações e realizações concretas desamparadoras, pois o desamparo primário é inerente à constituição do sujeito; o secundário, entretanto, decorre de sua condição de vida. Se o primeiro marca o humano, o segundo, mais circunstancial, vem sendo reforçado em meio a um contexto instável e inseguro. Assim, os níveis de angústia se elevam bastante, e, quando esta se torna incontrolável e invade o ego, o sujeito vive o desamparo, pois se sente sozinho, sem recursos e sem proteção. Surge, então, o transtorno de pânico, que, no nosso entender, expressa o desamparo atual.

Do ponto de vista da psiquiatria, a categoria transtorno de pânico é recente, e sua caracterização diagnóstica aparece no Manual Diagnóstico e Estatístico de Transtornos Mentais - DSM IV. (1995). Embora categorizada pela psiquiatria moderna, o fenômeno como tal já vem sendo observado há algum tempo; no entanto, importa lembrar que as categorizações das doenças têm a ver não só com a compreensão do fenômeno mas também com a sua incidência. A circunscrição de um transtorno aparece quando ele adquire maior visibilidade clínica. Nesse caso, a incidência do transtorno de pânico pode estar relacionada ao contexto de desamparo provocado pela fragilidade da lei simbólica que realçamos neste trabalho.

\section{O transtorno de pânico à luz da psiquiatria}

Com a criação da categoria transtorno de pânico - estabelecida no Manual Diagnóstico e Estatístico de Transtornos Mentais (DSM-III) e na Classificação Estatística Internacional de Doenças e Problemas Relacionados à Saúde (CID) -, o pânico ganha uma nova dimensão. A Organização Mundial de Saúde (OMS), em sua revisão baseada na Nona Conferência de 1975 para a concretização da décima edição da CID, já abordava a temática, e, então, no CID-10 (1996), classifica o transtorno de pânico como "transtornos neuróticos, transtornos relacionados com o stress e transtornos somatoformes". Especifica, ainda, colocando-o como transtornos ansiosos, que são definidos como "transtornos caracterizados essencialmente pela presença de manifestações ansiosas que não são desencadeadas exclusivamente pela exposição a uma situação determinada" (Organização Mundial de Saúde, CID-10, 1996, p. 333). 
Pereira (1997)

lembra que, até

a publicação

do DSM-III, em

1980, o emprego conceitual da palavra pânico em

psicopatologia era bastante raro e não sistemático.
Pereira (1997) lembra que, até a publicação do DSM-III, em 1980, o emprego conceitual da palavra pânico em psicopatologia era bastante raro e não sistemático. Por falta de um estatuto psicopatológico bem delimitado, o afeto de pânico era concebido como uma modalidade particular da angústia, podendo se manifestar de diferentes formas. Com o DSM-IV(1995), a definição do transtorno de pânico se especifica e fica mais clara.

Segundo a OMS, o transtorno de pânico é caracterizado como ataques recorrentes de ansiedade grave (ataques de pânico) que ocorrem de forma imprevisível, e não exclusivamente em situações determinadas. Nesses ataques, alguns sintomas físicos se fazem presentes, levando os sujeitos a desenvolver uma preocupação excessiva quanto ao medo da morte, de enlouquecer e de perder o controle da situação. Esses sintomas incluem distúrbios cardiorespiratórios - palpitações ou taquicardia, sensação de asfixia, de falta de ar e de sufocamento - calafrios, sudorese, tremores, desconforto ou dores abdominais, vertigem, náusea, desmaio, parestesia, etc. Também podem aparecer sintomas como desrealização ou despersonalização. Todo esse quadro pode vir ou não acompanhado de agorafobia (ansiedade de estar em locais ou situações das quais seria difícil escapar ou nas quais o auxílio não seria possível).

Vê-se na descrição acima a presença de um estado de desamparo, caracterizado pela ação constante da angústia, de sentimentos de ameaça à integridade física, de impossibilidade de obter amparo, e, por isso, o pânico de morrer, de enlouquecer, etc.

Para se estabelecer o diagnóstico de transtorno de pânico, os ataques devem apresentar frequência e características particulares. Os ataques de pânico podem ocorrer em uma variedade de transtornos de ansiedade, sendo básico para o diagnóstico diferencial observar o contexto no qual ocorre o ataque.
A ocorrência de um ataque de pânico não configura a instalação do transtorno de pânico. De acordo com o DSM-IV (1995) e o CID10 (1996), a característica mais importante para incluir os ataques no diagnóstico desse transtorno é que estes devem aparecer de forma inesperada, desvinculados de exposição a situações que quase sempre causam angústia, embora, depois de instalado o transtorno, outros tipos de ataque de pânico também possam ocorrer.

O ataque de pânico está descrito no DSM-IV como "um período distinto, no qual há o início súbito de intensa apreensão, temor ou terror, frequentemente associados com sentimentos de catástrofe iminente" (Organização Mundial de Saúde, DSM-IV, 1995, p. 375). Seus sintomas se desenvolvem abruptamente, podendo alcançar um pico em dez minutos. Os ataques têm duração variável e podem ir de alguns minutos a várias horas, mas, geralmente, duram entre cinco e trinta minutos, desaparecendo gradualmente, sem uso de medicação. Nesse momento, o sujeito vive o perigo como uma realidade presente e sem fim.

O transtorno de pânico propriamente dito deve ser diferenciado de outros transtornos mentais que também têm o ataque de pânico associado. Um dos requisitos fundamentais para diagnosticá-lo é, principalmente,

... a presença de ataques de pânico recorrentes e inesperados, seguidos por pelo menos 1 mês de preocupação persistente acerca de ter um outro ataque de pânico, preocupação acerca das possíveis implicações ou conseqüências dos ataques de pânico, ou uma alteração comportamental significativa relacionada aos ataques (Organização Mundial de Saúde, DSM-IV, 1995, p. 379)

As pessoas que tem esse transtorno possuem uma preocupação singular com as implicações ou consequências dos ataques de pânico. Após uma crise de pânico, o sujeito, geralmente, sente-se desmoralizado, desencorajado, envergonhado, ansioso, cansado, infeliz e com 
dificuldades em levar adiante rotinas habituais. Muitos dizem que é a pior sensação que já experimentaram, e não medem esforços para impedir sua repetição. No cerne dessas questões, é muito comum o temor à morte, à loucura, ao desequilíbrio emocional, etc. A situação é sempre de uma ameaça à vida, de algo catastrófico que está acontecendo ou muito próximo disso. Com o tempo, os ataques tendem a se repetir em intervalos variáveis. Todavia, o primeiro ataque é considerado um marco na vida dos sujeitos, uma reviravolta trágica.

Frequentemente, os sujeitos ficam angustiados, e o conteúdo dessa angústia é o temor de serem outra vez surpreendidos com um novo ataque, diante do qual se sentem impotentes. A preocupação com um novo ataque de pânico, muitas vezes, torna-se uma constante na vida dessas pessoas, que acabam recorrendo a medidas preventivas, evitando situações nas quais imaginam que não obterão ajuda ou saída. A esquiva de situações, em muitos casos, pode prejudicar a capacidade de a pessoa realizar atividades cotidianas, comprometendo de modo significativo seu comportamento e sua qualidade de vida. Quando não se consegue evitar, essas situações são suportadas com acentuado sofrimento ou com ansiedade acerca de ter um ataque de pânico ou sintomas tipo pânico. Além disso, muitas dessas pessoas também têm intensos sentimentos de ansiedade, seja ela focalizada ou não; outras demonstram excessiva apreensão acerca do resultado de atividades rotineiras, em especial, relacionadas à saúde ou à separação de pessoas queridas.

Em função dessa preocupação excessiva com um novo ataque, é comum o aparecimento da agorafobia, sintoma típico, embora nem sempre presente. Daí existirem dois tipos básicos de transtorno de pânico: os que apresentam agorafobia e os que não têm agorafobia. O curso de ambos é bastante variável.

Ressaltamos a necessidade de amparo desses sujeitos no alívio da grande angústia que experimentam nesses momentos. Quanto a isso, Pereira (1997) acrescenta que, já nas descrições freudianas dos ataques de angústia, o desenrolar do acesso estava ligado a acontecimentos de separação brutal de seres muito próximos ou de dificuldades em situações que antes representavam segurança e proteção para o sujeito. Pensamos que essa insegurança tão exacerbada na atualidade - pode estar denunciando a insuficiência da lei dos homens, que deveria assegurar a estabilidade.

A característica do transtorno, a de ter associado a ele experiências de separação, remete à angústia de separação, e, em consequência, ao confronto com a castração, à interdição. A sensação de desamparo que algumas pessoas vivenciam a partir disso revela o quanto o amparo é fundamental e é a lei que garante a segurança tão clamada. Suportar o desamparo é poder assumi-lo e, como consequência, poder também admitir a castração, a finitude e a presença de uma lei que regule as relações - os amparos. A impotência que os sujeitos portadores de pânico vivenciam diante das crises escancara seus desamparos, fazendo-os experimentar uma grande angústia, que, por sua vez, está remetida à angústia da castração. Em alguns sujeitos, nos quais essa inscrição da falta se dá de modo precário, quando colocados em uma situação que exija deles assumir o desamparo e a limitação própria do sujeito castrado, respondem com a crise de pânico.

\section{O pânico na perspectiva psicanalítica}

Perpassando os textos psicanalíticos que abordam a questão do pânico, percebemos que não existe um discurso psicanalítico único e homogêneo, mas vários, segundo o referencial teórico privilegiado. Apesar disso, todos acabam recorrendo aos textos fundadores de Freud, dada a sua importância.

O interesse pelo pânico na psicanálise, em geral, surge quando se trata de especificar os estados 
ansiosos intensos, extremos, embora, de acordo com Pereira (1999), não estejamos muito próximos de uma elaboração desenvolvida a tal ponto de situar o pânico de forma clara em relação à teoria da angústia.

A leitura dos textos freudianos nos mostra que, desde o início, os ataques repentinos, extremos e incontroláveis de angústia eram concebidos como distintos das outras formas ansiosas.

O transtorno de pânico tem a característica de não preparo que submete o eu a um estado de angústia avassaladora. Embora a angústia seja tanto uma reação como uma preparação para o perigo, dependendo da intensidade, ela pode tornar a defesa impossível e, em vez de facilitar a fuga, pode paralisar o sujeito e deixá-lo absolutamente incapaz de se defender. Quando a angústia se desenvolve de uma tal forma que invade por completo o mundo afetivo do ego, tornando-se incontrolável, a preparação para o perigo não tem lugar, e o ego fica totalmente submerso e desamparado. É o que ocorre no pânico.

Podemos compreender os estudos freudianos sobre o desamparo como correlativos aos estudos da angústia. A abordagem da neurose de angústia feita por Freud (1894-1895/1975a) levantou os elementos essenciais para situar o que seria ogerme da elaboração metapsicológica do desamparo e, ainda, correlativamente, dos atuais ataques de pânico.

Quando descobriu o estado de expectativa ansiosa, foi possível a Freud (1894-1895/1975a) postular a primeira explicação da natureza da angústia, que, na neurose de angústia, é uma descarga de excitação sexual acumulada que não encontrou um modo de ab-reação adequado. Trata-se do que Freud chamou de ausência da libido psíquica. Por causa dela, os sintomas somáticos ganham realce, pois através destes se descarrega a excitação sexual.

No segundo momento da elaboração da primeira teoria da angústia, sem deixar de ser inscrita no corpo, a angústia passou a ser estudada no registro da vida psíquica. Aqui a angústia pulsional se destacou, evidenciando o perigo pulsional. Os estímulos e excitações muito fortes psiquicamente não elaborados são sentidos pelo sujeito como um ataque, uma ameaça, um perigo. Para se defender, o ego recorre ao recalque, o que levou Freud à ideia de o recalque ser a causa da angústia.

Ao reformular a teoria das pulsões, em 1920, com a introdução da pulsão de morte, Freud (1926/1975d) foi levado a repensar a sua primeira teoria da angústia e a destacar que, além da angústia pulsional causada pelo perigo pulsional, existe uma angústia fundamental e originária, que tem como protótipo o nascimento. Ela serve de modelo para todas as outras angústias que se repetirão ao longo da vida. O recalque seria um dos mecanismos criados pelo ego para se defender da angústia mais primitiva, originária. O perigo contra o qual o ego se defende é o de separação entre mãe e filho; a partir daí, Freud chega a uma nova ideia: é a angústia que promove o recalque, e não o contrário, como dissera antes.

Quando admitiu, no estado de desamparo, uma causa fundamental da angústia, Freud (1926/1975d) atenuou o caráter ameaçador do perigo pulsional, enfatizando o estado de total desamparo do ser humano - Hilflosigkeit. Aqui a noção de perigo é redimensionada, e o perigo do qual ele precisa se defender é o do desamparo, uma condição em que o ser humano não tem os recursos necessários para ajudar-se a si próprio, precisando da ajuda do outro para sobreviver. Por causa disso, para sobreviver, ele precisa ser amparado.

Ao apontar isso, Freud (1926/1975d) coloca o desamparo como uma experiência estruturante para o sujeito, porque com ele o sujeito exprime uma atitude de apelo em direção ao outro, um grito de socorro de alguém que precisa de ajuda. Ele leva a pessoa a abrir mão das próprias ambições fálicas e da autossuficiência narcísica e das ilusões de onipotência a fim de sobreviver. Nesse espaço de abertura, ele pode constituirse como sujeito. 
Embora o desamparo primário que acompanha qualquer ser humano desde o nascimento esteja no fundamento do sujeito, isto é, seja uma condição fundamental independentemente de suas realizações concretas nas situações desamparadoras, na atualidade, essas situações parecem exacerbadas ao extremo: assumem feição trágica, com o caráter extremo do pânico em decorrência das condições de vida, e atravessam a existência das pessoas.

No nosso entender, como figura clínica, ele representa uma variação moderna do quadro fóbico que mostra, mais claramente, a relação atual da fragilidade da lei simbólica com o desamparo. Trata-se de uma experiência de angústia extrema que invade o ego de forma incontrolável e inesperada, sem dar-lhe chance de defesa. É a angústia que perde o caráter defensivo de autoconservação e de alerta ao perigo, e, de tão intensa, deixa o ego completamente invadido, desamparado. Além de se caracterizar como um afeto extremo de angústia, o pânico também apresenta relações com a fobia, uma vez que nele também estão presentes sintomas fóbicos. Contudo, ele traz uma especificidade: ocorre uma espécie de conversão da angústia para sensações corporais, experimentando o sujeito a ameaça diretamente no real do próprio corpo. Os ataques podem vir acompanhados de vários sintomas físicos, como: suor, tremores, calafrios, diarréia, vertigem, congestão e distúrbios nas atividades digestivas (náusea, vômito, alteração no apetite). Todos eles aparecem com o mesmo matiz afetivo - a ansiedade - e não, necessariamente, se originam de uma ideia recalcada. Pela presença marcante de somatizações, a sensação de estar morrendo invade a experiência afetiva do pânico, paralisando o sujeito.

De que maneira associamos o transtorno de pânico com a fobia? O que a caracteriza? Para responder a essa pergunta, lembremos que, no texto $O$ aparelho psíquico e o mundo externo, Freud (1938-1940/1975e) destacou que, na tentativa de conciliar as duas forças
- o mundo externo e o mundo interno -, o ego é duplamente ameaçado: uma ameaça provém dos perigos da realidade externa, outra, dos perigos do próprio id, cuja intensidade excessiva de estímulo pode prejudicar o ego tal como os estímulos excessivos do mundo externo. Assim, ele precisa defender-se tanto do mundo externo quanto do seu mundo interno, das exigências excessivas. Para lidar com as tendências conflitantes coexistentes no sujeito, o ego estabelece uma espécie de acordo entre a duas demandas. Trata-se de uma formação de compromisso entre o material inconsciente do sujeito, que é intolerável, e as exigências defensivas. Por meio desse acordo, as duas forças opostas que entraram em luta podem reconciliar-se e são representadas no sintoma. A depender do tipo de defesa utilizado, o indivíduo pode encaminhar-se para um modo de funcionamento psíquico específico que possibilita diferenciar uma nosologia.

Nas fobias, percebemos a imposição de representações, carregadas pelo estado emocional de angústia, de medo. De acordo com a natureza do objeto temido, podemos ter as fobias comuns, que se caracterizam pelo medo exagerado de coisas temidas por todos em alguma medida - noite, solidão, morte, doença, cobras, etc. - ou contingentes, cuja marca é o medo de condições especiais que não inspiram medo ao homem normal agorafobia, fobias de locomoção, etc. - casos em que o estado emocional só se manifesta sob condições especiais, que o paciente evita cuidadosamente.

No quadro fóbico, o sujeito enfrenta seu conflito emocional interno e a ansiedade, tentando recalcar os pensamentos e os impulsos perturbadores. Quando fracassa o recalque, ele desloca seu conflito para um lugar ou situação no mundo exterior, tentando confinar a ansiedade a tal situação, que passa a representar, simbolicamente, seu conflito interno. Assim, o perigo interno projeta-se para o mundo externo, e, com isso, o sujeito pode evitar a situação na 
Pereira (1997, p.76) nos lembra que "a descrição freudiana dos acessos de angústia observados na Angstneurose está muito próxima da que fol operacionalmente estabelecida hoje em dia para o transtorno de pânico". tentativa de amenizar a ansiedade. Em vez de ficar com um conflito interno, porque a formação de compromisso não foi suficiente para manter a ideia recalcada, o ego projeta para fora de si o perigo, desviando o conflito para um objeto, que, por conta do deslocamento, se torna um objeto fóbico, que passa a ser evitado. O mecanismo de uso da evitação apresenta-se ao sujeito como o principal meio de solucionar problemas. As defesas auxiliares de simbolização, deslocamento e racionalização servem para possibilitar tal mecanismo (Freud (1909/1975b). Entretanto, essa solução é apenas temporária e aparente, pois o conflito básico sempre volta, de modo a, com frequência, poder haver mudança na simbolização ou no deslocamento, o que resulta na substituição de antigas fobias por outras novas. Chemama (1995) nos lembra que o objeto fóbico surge a fim de suprir o Nomedo-Pai que falhou, e a fobia surge como uma suplência a essa função paterna deficitária.

Embora no transtorno de pânico exista sempre um caráter fóbico, o objeto fóbico quase inexiste, pois a reação psicossomática prevalece e esta não tem objeto definido. As exigências da realidade externa parecem assumir o lugar de objeto fóbico, avassalador e castrador, similar, às vezes, ao que acontece com o paranóico, que se vê perseguido por outro devorante e aniquilador que está em toda parte. No pânico, o ego tenta fugir à realidade intolerável, mas, acuado, vive seu desamparo de forma extrema, no real do corpo, convertendo para este o sofrimento. Sofre e cai literalmente, pois desmaia, desfalece, fica paralisado.

Pereira (1997, p.76) nos lembra que "a descrição freudiana dos acessos de angústia observados na Angstneurose está muito próxima da que foi operacionalmente estabelecida hoje em dia para o transtorno de pânico". Todavia, se na neurose de angústia a ansiedade guarda semelhanças com a insatisfação sexual, no pânico, ela se relaciona com um contexto não acolhedor, no qual o desamparo se faz muito presente.

\section{Pânico e desamparo}

De fato, cada época está marcada por angústias, desamparos e dificuldades próprias; a questão seja talvez a de determinar, na época atual, os fatores geradores do desamparo e de esclarecer a especificidade de tal desamparo que, no caso, recebeu a qualificação de transtorno de pânico.

Partindo da ideia de que a lei humaniza e ampara, quando ela falha, pode haver aí um favorecimento da angústia do desamparo, à qual o sujeito pode responder de formas variadas, mas aqui chamamos a atenção para o desenvolvimento do transtorno de pânico como manifestação desse desamparo atual, que é consequência dos modos de se fazer cumprir a lei.

A angústia do ataque de pânico tem como determinante a ocorrência de uma situação traumática, cuja essência é a experiência de desamparo vivido pelo ego devido ao acúmulo de excitação interna com a qual ele não pode lidar. Assim, segundo Rocha (2000, p. 67), o transtorno de pânico emerge como uma "tentativa desesperada para representar de alguma forma a inominável angústia do desamparo na sua forma extrema ...".

Freud (1926/1975d) situa o desamparo muito além de uma condição acidental e traumática ou como regressão a um estado primitivo de insuficiência psicomotora. Para ele, o desamparo diz respeito a uma fundamental falta de garantias para o funcionamento do aparelho psíquico, pois este é incapaz de promover uma apreensão simbólica definitiva para questões fundamentais do sujeito, como a própria morte, o destino, o investimento sexual do corpo, etc. Na própria ordem simbólica, há algo que é frágil, mas que, paradoxalmente, se abre para o mundo dos possíveis, a partir do qual o sujeito pode se constituir. Apesar dessa lacuna, a lei simbólica pode se exercer de maneira a atender as condições mínimas necessárias ao bem-estar do sujeito. Pensamos que, no pânico, devido ao desamparo no qual o sujeito está submerso, 
essa fragilidade toma proporções excessivas que, por isso mesmo, o deixa desamparado. É o encontro súbito e inesperado com essa dimensão da falta de garantias absolutas ante o possível que constitui o ponto de partida e de ancoragem para a crise de pânico, que aqui toma proporções que se amplificam porque as diferentes formas de a lei se fazer presente têm sido questionadas.

Para abordar a relação entre pânico e desamparo, recorremos também à tese de Pereira (1999), e a preferência pelos seus comentários leva em conta o fato de ele, como psiquiatra e psicanalista, conseguir articular com propriedade a questão do transtorno de pânico pelo viés da psicanálise, além de ser um bom leitor de Freud. Por isso, pensamos com ele que o pânico representa apenas uma das várias possibilidades de o sujeito se relacionar com o seu próprio desamparo, em um esforço extremo de pré-simbolização, pois antecipa a experiência do morrer - como representação imaginária da entrada na própria morte. Como lembra, "... o sujeito acometido de ataques de pânico... é, sem dúvida, uma pessoa mais perto do conhecimento profundo da condição de desamparo fundamental da existência humana..." (Pereira, 1999, p. 249). Por estar em contato direto com a impossibilidade de o aparelho psíquico simbolizar o conjunto do real e de seus possíveis, o sujeito em pânico é alguém que vive sob a constante ameaça de desabamento do seu mundo, que assume, para ele, a forma concreta do perigo de morrer, chegando a experimentar essa ameaça diretamente no real do seu corpo. Essa sensação de estar morrendo ocupa o lugar central da experiência afetiva do pânico, escancarando a finitude humana, que pode tanto mobilizar a vida quanto paralisar o sujeito - tal como acontece no pânico.

Segundo Pereira (1999), essa relação singular do sujeito em pânico com a morte é problemática, na perspectiva psicanalítica, pois a teoria freudiana mostra que a morte-própria não é representável no inconsciente. Neste, a morte é sempre tratada como registro positivo, como a morte de outrem. Apesar de nada se poder saber, seguramente, sobre a própria-morte, esse irrepresentável ocupa um lugar central que se inscreve no sujeito a partir de um discurso que vem do outro. Assim, podemos criar da morte uma imagem, uma representação, um fantasma, a partir do discurso do outro. Além disso, a morte é prometida pela palavra do outro e ratificada pelas experiências de separação, sobretudo as da morte do ser amado. Tais experiências trazem consigo a possibilidade de inscrever algo da morte-própria no inconsciente. O lugar vazio circunscrito pelo próprio inconsciente em relação ao qual o sujeito se vê sempre sem ajuda e sobre o qual os temas e fantasmas da morteprópria se inscrevem constitui fonte potencial de pânico e terror.

Apesar do caráter ameaçador do desamparo, ele se apresenta como uma experiência estruturante, uma vez que, em um estado de desamparo, o sujeito não tem como se defender sozinho e precisa de ajuda, tendo que abrir mão de toda sua autossuficiência narcísica, pois só com a colaboração do outro ele pode solucionar o problema no qual se encontra. O desamparo, portanto, leva o sujeito a abrir-se à alteridade. Surge, então, uma questão paradoxal: essa abertura à alteridade implica um pedido de amparo. Quando isso se concretiza, o sujeito percebe o outro como alguém que merece cuidado, tal como ele. Aquele que não pode ser amparado dificilmente desenvolve essa preocupação com o outro; em consequência, se esse outro não tem para ele a importância devida, não faz sentido seguir uma regra, respeitar a lei, pois, para que a lei se estabeleça, é necessário um terreno preparado para assimilá-la, e isso é favorecido pelo amparo, do mesmo modo que este acontece em referência à lei. Se falha a lei, falha o amparo, e vice-versa. Desse modo, lei e desamparo, paradoxalmente, tornam-se constituintes do sujeito, porque trazem consigo um apelo em direção ao outro, um apelo que obriga o sujeito a abrir mão de suas ilusões de onipotência porque ele reconhece o outro como fundamental à sua existência, e só a partir do registro da castração isso é possível. 


\section{Lei simbólica e pânico}

Compreendemos que é a lei que, pondo limite à autossuficiência narcísica, indica que o sujeito precisa do Outro para sobreviver, para se identificar, para existir. Para viver no mundo de trocas simbólicas, é fundamental que ele perceba que o outro, assim como ele, necessita também de amparo. Todavia, o contexto atual do individualismo exacerbado impede que se escute tal apelo, tanto do sujeito quanto do outro. Não sendo escutados, vêem-se isolados, desamparados.

Concordamos com Rocha (1999) quando afirma que, ao contrário da condição humana de desamparo, da qual ninguém escapa, das situações de desamparo, as pessoas podem se livrar. Dissemos antes que o desamparo indica um grito de apelo ao outro que precisa ser ouvido. Se isso ocorre, saídas possíveis ao estado de desamparo podem ser visualizadas; entretanto, se isso não acontece, a situação de desamparado é reforçada e ele pode entrar em desespero.

Podemos colocar que o pânico se dá quando o sujeito se encontra, inesperadamente, com a dimensão da falta, e é a função paterna que viabiliza suportá-la, inscrevê-la, através de sua Lei. Se o pai - ou suplentes - como representante da lei falha, o desamparo, subitamente, se impõe, lançando o sujeito em uma falta de garantias de tal ordem que ele entra em pânico.

Salientamos aqui esse momento especial que desencadeia a crise. Não é frequente, nos transtornos neuróticos, a referência a um estado de crise que irrompe subitamente. Parece ser algo peculiar aos quadros fóbicos, nos quais algo exterior mobiliza a angústia. Isso nos faz lembrar o que ocorre com a psicose. Nesta, há o momento da injunção que precede o surto, que, por sua vez, acontece como resposta defensiva do sujeito no instante em que foi chamado a comparecer com uma referência de lei que lhe falta, ou seja, é o momento em que ele é chamado a dar um tipo de resposta em que se faça presente o Nome-do-Pai - o registro do simbólico instituído a partir da falta - mas, por não possuir tal inscrição, o sujeito se depara com o vácuo, com o nada, e é então que ele se esvai e surta; para tamponar esse vácuo, alucina.

Fazendo um paralelo, guardadas as devidas especificidades, vemos que algo semelhante acontece no momento anterior ao ataque de pânico: o sujeito é convocado a comparecer ou a reagir com as insígnias paternas que the dão garantias e segurança, e como elas lhe foram delegadas de modo débil e falho, cai no desamparo e entra em pânico. O que dá singularidade ao sujeito em pânico e o diferencia do psicótico é que, enquanto neste a inscrição da lei é ausente, forcluída, naquele, ela se faz presente, mas de modo falho. Poderíamos avançar um pouco e acrescentar que, durante a crise de pânico, a referência à lei aparece sob a forma de sintoma corporal, o qual também emerge como uma espécie de conversão para o corpo da angústia vivenciada. Esse sintoma corporal, no extremo, limita o sujeito, e esse limite passa a ser vivido no real do corpo paralisado.

Apesar da especificidade da presença de distúrbios psicossomáticos, em que o corpo denuncia uma sobrecarga de excitação incapaz de ser simbolizada e que, por tal razão, escoa para o corpo, o transtorno de pânico também apresenta sintomas fóbicos, podendo mesmo ser entendido como uma fobia típica da atualidade.

No contexto do pânico, o sujeito se vê em dificuldade de recorrer às substituições internas necessárias para configurar uma formação de compromisso e, assim, poder lidar com o conflito. Não tendo tempo para construir uma formação de compromisso, ele recalca o conflito e o substitui, desloca. Nessas condições, ele apela para o outro, que, insuficiente para atender sua demanda, não o ampara. Como não tem o outro para ajudá-lo, ele fica acuado e faz um corte abrupto com a realidade, ficando 
paralisado, e, por tal razão, ele sofre, entra em pânico.

Embora no transtorno de pânico exista sempre um caráter fóbico, o objeto fóbico não fica tão evidente. O que aparece mais intensamente é a reação psicossomática, sem objeto definido. As exigências da realidade externa parecem assumir o lugar de objeto fóbico, avassalador, e castrador; pensamos que esse caráter aparentemente aniquilador pode estar relacionado com a insuficiência de um contexto que falha no limite e por isso desampara.

\section{Veridiana Alves de Sousa Ferreira Costa}

Mestre em Psicologia Clínica, Psicóloga, Universidade Federal Rural de Pernambuco, Pernambuco - PE - Brasil.

E-mail: veridianacosta@hotmail.com

\section{Edilene Freire de Queiroz}

Doutora em Psicologia Clínica, Psicanalista, Universidade Católica de Pernambuco, Pernambuco - PE - Brasil.

E-mail: equeiroz@unicap.br

Endereço para envio de correspondência:

Fazenda Saco,S/n, Caixa postal: 063, Serra Talhada, Pernambuco - PE - Brasil. CEP 56.900-000

Recebido 4/11/2009, 1a Reformulação 9/11/2010, 2a Reformulação 4/1/2011, Aprovado 4/4/2011.

\section{Referências}

Birman, J. (1999). Mal-estar na atualidade. A psicanálise e as novas formas de subjetivação. Rio de Janeiro: Civilização Brasileira.

Chemama, R. (1995). Dicionário de Psicanálise (F. F. Settineri, trad.). Porto Alegre: Artes Médicas.

Dor, J. (1991). O pai e sua função em psicanálise (D. D. Estrada, trad.). Rio de Janeiro: Jorge Zahar.

Enriquez, E. (1999). Da horda ao Estado. Psicanálise do vínculo social (T. C. Carreteiro, \& J. Nasciutti, trad.). Rio de Janeiro: Jorge Zahar.

Freud, S. (2006) O mal-estar na civilização, In Edição standard brasileira das obras psicológicas completas de Sigmund Freud. (J. Salomão, trad., Vol. 21,). Rio de Janeiro: Imago (Trabalho original publicado em 1930),

Freud, S. (1975a). Sobre os fundamentos para destacar da neurastenia uma síndrome específica denominada "neurose de angústia" In Edição standard brasileira das obras psicológicas completas de Sigmund Freud (J. Salomão, trad., Vol. 3, pp. 89-118). Rio de Janeiro: Imago (Trabalho original publicado em1894-1895).

Freud, S. (1975a). Obsessões e fobias: seu mecanismo psíquicoe sua etiologia. In Edição standard brasileira das obras psicológicas completas de Sigmund Freud (J. Salomão, trad.,Vol. 3, pp. 73-88). Rio de Janeiro: Imago (Trabalho originalpublicado em 1894-1895).

Freud, S. (1975b). Análise de uma fobia em um menino de cincoanos. In Edição standard brasileira das obras psicológicas completasde Sigmund Freud (J. Salomão, trad., Vol. 10, pp.11133). Rio de Janeiro: Imago (Trabalho original publicado em 1909).

Freud, S. (1975c). Totem e tabu. In Edição standard brasileira das obras psicológicas completas de Sigmund Freud (J. Salomão, trad., Vol. 13, pp. 11-162). Rio de Janeiro: Imago (Trabalho original publicado em 1912-1913).

Freud, S. (1975d). Inibições, sintomas e ansiedade. In Edição standard brasileira das obras psicológicas completas de Sigmund Freud (J. Salomão, trad., Vol. 20, pp.79-171). Rio de Janeiro:Imago (Trabalho original publicado em 1926).

Freud, S. (1975e). O aparelho psíquico e o mundo externo. In Edição standard brasileira das obras psicológicas completas de Sigmund Freud (J. Salomão, trad., Vol. 23, pp. 209-221). Rio de Janeiro: Imago (Trabalho original publicado em 1938-1940)..

Lacan, J. (1999). As formações do inconsciente. In O seminário. Livro 5 (J. e J. Miller, trad.). Rio de Janeiro: Jorge Zahar.

Lacan, J. (1995). O seminário. Livro 4. A relação de objeto (J. e J. Miller, trad.). Rio de Janeiro: Jorge Zahar. (Trabalho original publicado em 1956-1957).

Organização Mundial de Saúde. (1996). CID-10, Classificação Estatística Internacional de Doenças e Problemas Relacionados à Saúde (3a ed., Vol. 1). São Paulo: Editora da Universidade de São Paulo.

Organização Mundial de Saúde. (1995). DSM-IV, Manual Diagnóstico e Estatístico de Transtornos Mentais (4a ed). Porto Alegre: Artes Médicas.

Pereira, M. (1997). Contribuição à psicopatologia dos ataques de pânico. São Paulo: Lemos Editorial.

Pereira, M. (1999). Pânico e desamparo: um estudo psicanalítico. São Paulo: Escuta.

Rocha, Z. (1999). Desamparo e metapsicologia. Para situar o conceito de desamparo no contexto da metapsicologia freudiana. Síntese Revista de Filosofia, 26(86), 331-346.

Rocha, Z. (2000). Os destinos da angústia na psicanálise freudiana. São Paulo: Escuta. 